\title{
Guiding the design of behavioural and lifestyle modification interventions for risk reduction, prevention, and treatment of non-communicable diseases in low- and middle-income countries: An overview of relevant literature
}

Abel Negussie ( $\square$ abelnegussie@ymail.com )

Yirgalem Hospital Medical College, Yirgalem, Ethiopia https://orcid.org/0000-0001-7516-6169

\section{Adamu Addissie}

Department of Preventive Medicine, School of Public Health, Addis Ababa University, Addis Ababa, Ethiopia

\section{Alemayehu Worku}

Department of Preventive Medicine, School of Public Health, Addis Ababa University, Addis Ababa, Ethiopia

\section{Eshetu Girma}

Department of Preventive Medicine, School of Public Health, Addis Ababa University, Addis Ababa, Ethiopia

\section{Research Article}

Keywords: chronic disease prevention, lifestyle-related risk behaviour, lifestyle modification, behavioural intervention, low- and middle-income countries

Posted Date: April 17th, 2023

DOI: https://doi.org/10.21203/rs.3.rs-1033454/v2

License: (c) (i) This work is licensed under a Creative Commons Attribution 4.0 International License. Read Full License 


\section{Abstract}

\section{Background}

The increasing burden of chronic non-communicable diseases (NCDs) in low- and middle-income countries (LMICs) calls for the development and dissemination of effective and viable interventions. In this respect, behavioural and lifestyle modification interventions (BLMIs) offer the most effective means of addressing the underlying lifestyle behaviours associated with NCDs at multiple disease prevention levels (primordial, primary, and secondary). This review aims to provide an overview of key features and components of BLMIs, as well as practical considerations when implementing in LMIC settings.

\section{Methods}

An exploratory approach was used to provide an overview of salient issues in the design of BLMIs; and the PubMed and Google Scholar databases, as well as grey literature, were searched. Based on the review's aim, the most important issues/themes were identified using a narrative thematic synthesis and analysis approach.

\section{Results}

Thirty-three publications were included as the most relevant literature to the topic, and eight overarching themes were identified: understanding the target health behaviour; using behavioural/psychological theories; applying behaviour change techniques/strategies; providing effective support and follow-up; intervention delivery formats and providers; cultural sensitivity; feasibility consideration; and addressing multiple lifestyle behaviours.

\section{Conclusion}

Targeting lifestyle and behavioural modification interventions with a proper understanding of their essential design components and practical contextual considerations is crucial in reducing the rising burden of NCDs in LMICs. Future direction on the importance of conducting original researches and systematic reviews on the subject was also emphasized.

\section{Background}

Non-communicable diseases (NCDs) - primarily cardiovascular disease, cancer, chronic respiratory disease, and diabetes - have become the main health concern for the majority of countries worldwide [13]. Many of these are classified as lifestyle-related health conditions and they share one or more common lifestyle behaviours, such as excess body weight/obesity, low levels of physical activity, poor nutrition, and substance use $[4,5]$. To tackle these behavioural risk factors, several interventions have been proposed and implemented around the world, especially in high-income countries. Likewise, there is an urgent global need for successfully addressing the underlying lifestyle behaviours associated with these diseases, and it 
is of great importance to examine ways of translating evidence of intensive research trials for low socioeconomic populations and settings $[6,7]$.

Behaviour change can be difficult and complex, but if it is approached in a scientific and systematic way, people can change their behaviours and improve their health [8]. Behavioural and lifestyle modification interventions (BLMIs) involve a lifelong process of incrementally building more health-promoting practices into daily routines, thereby shifting the overall behavioural balance in favor of habits that reduce NCD risk. Behaviour change techniques (BCTs) have become the foundation of BLMls and there are multiple BCTs and strategies commonly employed for changing unhealthy behaviours, including establishing behavioural goals, self-monitoring, individual counseling using motivational interviewing, training in problem-solving procedures, making changes to the environment to support positive changes, and relapseprevention planning $[9,10]$. However, assessing health behaviours and assisting in their modification requires a culturally competent, individual, or patient-centered orientation rooted in an appreciation of the broader social, economic, cultural, and gender contexts [8, 11].

The striding burden of NCDs in low- and middle-income countries (LMICs) calls for the development and dissemination of effective and feasible interventions $[12,13]$. Consequently, initiatives for promoting healthy behaviours should be at the forefront across all prevention strategies (i.e., primordial, primary, and secondary), as they offer ultimate options to successfully address the underlying lifestyle behaviours associated with NCDs. Yet, many LMICs face challenges in implementing robust prevention strategies to combat NCDs, and the promise for identifying effective and feasible BLMIs in LMICs is far behind [14-16]. A possible explanation for this significant setback could be a lack of knowledge about how to design BLMls and tailor them to the target segment of the general population.

The purpose of this narrative review is to provide overview of BLMls with implications for the risk reduction, prevention, and treatment of NCDs in LMICs. The following research questions framed our review: (1) what are the key features of BLMIs? (2) what important practical aspects need to be considered in designing of BLMIs in LMIC contexts? As this literature review covers a breadth of topics that are applicable across multiple BLMIs, a systematic or scoping review was not feasible and appropriate to address the research questions. Therefore, rather than aggregate or summarize details in response to a narrow research question, an exploratory approach was taken to provide an overview of pertinent issues in the design of BLMIs.

\section{Methods}

\section{Study design}

A narrative review methodology was considered the best fit with our larger study aim because of the wide range and heterogeneous nature of the literature relating to our research question [17]. Besides, when reviewing the literature, greater emphasis was placed on relevant literature that conceptually converged with the review's purpose. 


\section{Search method}

To identify relevant papers, the PubMed and Google Scholar databases, as well as grey literature, were searched. The search was comprehensive but not exhaustive, and we tried to narrow enough and focus the effort on the most pertinent survey of publications. Various combinations of the following keywords or general search terms were used: lifestyle behaviour; behavioural modification; behavioural intervention; behaviour change intervention; health promotion intervention; non-communicable disease; and chronic disease. The search was limited to papers published in English between January 2000 and December 2020, with recent articles prioritized when feasible. References within relevant articles were also screened in order to identify additional relevant literature. The corresponding author of this paper selected and screened the relevant literature between February and June 2021, and consistency was checked by the other authors.

\section{Rationale and basis for identifying key literature}

The included literatures were selected based on their importance to the research topic and research questions. However, the review remains selective due to the authors' focus on highlighting key features of BLMI design rather than presenting a comprehensive compilation of data. Partly, the selectivity is owed to a lack of available guidance on BLMIs in LMIC contexts and populations. Where the publication was found authoritative and the issues discussed appeared to be applicable in LMIC contexts, the paper was given higher consideration for inclusion as relevant literature in the review.

As our review topic requires a broader scope of BLMls, the following inclusion criteria were considered to determine if the literature is eligible: (1) Papers: peer-reviewed scientific journals, grey literature, commentaries, or editorials that focus on BLMI-related topics or at least one of the research questions; (2) Intervention target-group could include the apparently healthy general population, those at risk of developing NCDs (e.g., obese/overweight population groups), or people with chronic NCDs; (3) Intervention-type: any intervention that uses one or more BLMI strategies or approaches to reduce risk, prevent, or treat chronic NCDs. The following papers were excluded: (1) Papers focusing on issues not specific to BLMIs; (2) Studies focusing on issues not relevant to LMIC contexts.

\section{Quality appraisal}

Due to the nature of the included papers, i.e., some are books, commentaries, and editorials, which can be difficult to get specific quality assessment guides/checklists for, as well as the review's overall purpose of providing an overview of the subject, quality appraisal of the selected papers was not applicable.

\section{Data extraction, synthesis and analysis}

Data were extracted from the included papers using an Excel template to describe the author(s), year of publication, aim or focus, and main discussion topic of the papers in relation to BLMIs. Relevant key features and practical considerations of BLMIs were also identified across all included papers. 
A narrative thematic synthesis was used for reviewing the included literatures. Initially, an in-depth evaluation of included publications was carried out through comparing, contrasting and extrapolating contents and major discussion topics. The identified focus-topics from the literatures were then synthesized to form themes and topic categories. The findings were organized according to the objectives and referred to as 'themes' pertaining to important concepts and review questions. Finally, all content related to BLMls was summarized and presented as key issues/themes. The data extraction, synthesis, and analysis were conducted by the corresponding author, and the other review authors independently cross-checked the process to verify its appropriateness and reliability.

\section{Results}

A total of thirty-three publications were ultimately selected as relevant and formed the basis of this narrative review, including four books, eight original research articles, twenty reviews, and one editorial. The detailed summary of the selected relevant literature is presented in Table 1.

tble 1: List of relevant publications included in the review 


\section{Author Publication Title (publication type year) \\ Aim/focus of the paper \\ Relevant issue(s) discussed}

Evidence-based
Artinian et

l. (2010)

-37]

Barrera et Review

ıl. (2013) article

39]

3artholomew Book

tt al. (2016)

-20] article

Book

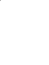

Review
Interventions
to promote
physical
activity and
dietary lifestyle
cardiovascular
risk factor
reduction in
adults: a
scientific
statement from
the American
Heart
Association

\section{Cultural}

adaptations of

behavioral

health

interventions: a

progress

report

Planning
health
promotion
programs: An
intervention
mapping
approach

3esculides et Original al. (2008) research

-36]

\section{Best practices \\ in \\ implementing \\ lifestyle \\ interventions in \\ the \\ WISEWOMAN \\ program: \\ adaptable \\ strategies for \\ public health \\ programs \\ Best practices in implementing a variety of lifestyle interventions targeting cardiovascular disease risk factors}

3urke et al.

'2012) [27] research
Original

Using mHealth technology to enhance selfmonitoring for weight loss: a randomized trial

Jastro et al. '2010) [40]
Review article
Issues and challenges in
Stages in developing cultural adaptations, common elements, and the effectiveness of culturally enhanced interventions

Guide how to plan and develop health promotion programs using an intervention mapping framework

recommendations on

implementing physical

activity and dietary

interventions in adults
Cognitive-

behavioural

strategies, intervention

delivery strategies
Cultural

adaptation of behavioural interventions
Practical application of systematic and evidence-based approaches in using theories for developing health promotion programs

The importance of understanding behaviour change theory, training. staff, and tailoring interventions
Tested if self-monitoring diet using a mHealth technology only or combined with daily tailored feedback, was superior to using a traditional paper diary on weight loss and maintenance

Design and conduct of adapted interventions,
Use of technology in self -monitoring of diet and weightloss behaviours

Cultural adaptation of 
the design of culturally

adapted

evidence-based

interventions

Coupe et al. Original Tailoring

'2018) [42] research lifestyle

interventions

to low socio-

economic

populations: a

qualitative

study

Jeller et al. Review

'2017) [49] article

Glanz (eds) Book

'2008) [8]

Jlanz and

3ishop

'2010) [11]
Future

directions of

multiple

behavior

change

research

Health

behavior and

health

education:

Theory, research, and

practice

Review

article
The role of

behavioral

science theory

in development

and

implementation

of public health

interventions and their effectiveness

evidence-based interventions
How best to tailor weight loss lifestyle

interventions to low

socio-economic

populations

Discussed research

needs on multiple health

behaviour change

Comprehensive and in-

depth analysis of major health behaviour theories

Theory use for designing and conducting healthpromotion interventions
Cultural and other important considerations when designing and tailoring lifestyle interventions for low socioeconomic populations

Targeting multiple health behaviour change interventions to impact NCDs

Behavioural theories

Multiple determinants and levels of health behaviour, behavioural theories and their use in health behaviour intervention

Practicality and external validity of behavioural trials, contextual and real-world considerations in designing trials

The importance of using and applying behavioural theories in planning of health promotion programs

Key components of effective lifestyle interventions, behaviour change strategies, continued support 
「ohnston and

Moreno

(2014) [30]

Kang et al. Original (2010) [34] research

-inke et al. Review

(2014) [21] article
Promotion of long-term adherence to a healthy lifestyle

Comparison of

family partnership intervention care vs conventional care in adults with poorly controlled type 2 diabetes in a community hospital: a randomized controlled trial

Applying psychological theories to promote healthy lifestyles
Long-term adherence of healthy lifestyle

behaviours

Effectiveness of family partnership intervention care for patients with poorly controlled type 2 diabetes

Description and application of commonlyused psychological theories and models
Behavioural strategies to achieving longterm adherence to healthy lifestyle

Importance of enhancing family support to improve diabetes control and selfcare behaviours

$\begin{array}{ll}\text { Family } & \text { Relationships between } \\ \text { support, } & \text { perceived family support, } \\ \text { medication } & \text { medication adherence } \\ \text { adherence and } & \text { and glycemic control } \\ \text { glycemic } & \\ \text { control among } & \\ \text { adults with } & \\ \text { type 2 diabetes } & \end{array}$

Michie and Abraham (2009) [9]

Michie et al. (2009) [10]

Michie et al. (2013) [25]

\begin{abstract}
Review article
\end{abstract}

\section{Review} article

Effective techniques in healthy eating and physical activity interventions:

A metaregression

\section{Low income} groups and behaviour change review of intervention content, effectiveness and theoretical frameworks

$\begin{array}{ll}\text { Original } & \text { The behavior } \\ \text { research } & \text { change } \\ & \text { technique } \\ & \text { taxonomy (v1) } \\ & \text { of 93 } \\ \text { hierarchically }\end{array}$
interventions: a
Effectiveness of

behaviour change interventions designed to promote physical activity and healthy eating

\section{Effectiveness of} interventions targeting low-income groups to reduce smoking or increase physical activity and/or healthy eating behaviour change techniques taxonomy
Development of
The importance of family support for diabetes self-care behaviours
Psychological theories and models
Components and behaviour change techniques of effective interventions
Description of important list of behaviour change techniques for precise specification of
Evidence of effect and what type of interventions, in terms of content/techniques and theory-used, are effective in low-income groups 


\begin{tabular}{|c|c|c|c|c|}
\hline & & $\begin{array}{l}\text { clustered } \\
\text { techniques: } \\
\text { building an } \\
\text { international } \\
\text { consensus for } \\
\text { the reporting } \\
\text { of behavior } \\
\text { change } \\
\text { interventions }\end{array}$ & & $\begin{array}{l}\text { content of an } \\
\text { intervention in } \\
\text { behaviour change } \\
\text { interventions }\end{array}$ \\
\hline $\begin{array}{l}\text { Miller and } \\
\text { Pimatteo } \\
\text { (2013) [32] }\end{array}$ & $\begin{array}{l}\text { Review } \\
\text { article }\end{array}$ & $\begin{array}{l}\text { Importance of } \\
\text { family/social } \\
\text { support and } \\
\text { impact on } \\
\text { adherence to } \\
\text { diabetic } \\
\text { therapy }\end{array}$ & $\begin{array}{l}\text { The relationship between } \\
\text { social support and } \\
\text { treatment adherence in } \\
\text { patients with diabetes }\end{array}$ & $\begin{array}{l}\text { Social/family } \\
\text { support and } \\
\text { adherence to } \\
\text { diabetes treatment }\end{array}$ \\
\hline $\begin{array}{l}\text { Miller and } \\
\text { Rollnick } \\
\text { '2013) [28] }\end{array}$ & Book & $\begin{array}{l}\text { Motivational } \\
\text { interviewing: } \\
\text { helping people } \\
\text { change }\end{array}$ & $\begin{array}{l}\text { Application of } \\
\text { Motivational } \\
\text { Interviewing }\end{array}$ & $\begin{array}{l}\text { Practical } \\
\text { Motivational } \\
\text { Interviewing } \\
\text { strategies as a tool } \\
\text { for facilitating } \\
\text { behaviour change }\end{array}$ \\
\hline $\begin{array}{l}\text { Noar et al. } \\
\text { (2007) [41] }\end{array}$ & $\begin{array}{l}\text { Review } \\
\text { article }\end{array}$ & $\begin{array}{l}\text { Does tailoring } \\
\text { matter? Meta- } \\
\text { analytic review } \\
\text { of tailored } \\
\text { print health } \\
\text { behavior } \\
\text { change } \\
\text { interventions }\end{array}$ & $\begin{array}{l}\text { A meta-analytic review } \\
\text { on the effects of tailored } \\
\text { print health behaviour } \\
\text { change interventions }\end{array}$ & $\begin{array}{l}\text { Effectiveness and } \\
\text { importance of } \\
\text { tailoring health } \\
\text { behaviour change } \\
\text { messages }\end{array}$ \\
\hline $\begin{array}{l}\text { Noar et al. } \\
\text { (2008) [24] }\end{array}$ & $\begin{array}{l}\text { Review } \\
\text { article }\end{array}$ & $\begin{array}{l}\text { Applying } \\
\text { health } \\
\text { behavior } \\
\text { theory to } \\
\text { multiple } \\
\text { behavior } \\
\text { change: } \\
\text { considerations } \\
\text { and } \\
\text { approaches }\end{array}$ & $\begin{array}{l}\text { How to apply health } \\
\text { behaviour theory to } \\
\text { multiple behaviour } \\
\text { change }\end{array}$ & $\begin{array}{l}\text { Theory use in } \\
\text { multiple health } \\
\text { behaviours }\end{array}$ \\
\hline $\begin{array}{l}\text { ?ainter et al. } \\
\text { 2008) [23] }\end{array}$ & $\begin{array}{l}\text { Review } \\
\text { article }\end{array}$ & $\begin{array}{l}\text { The use of } \\
\text { theory in } \\
\text { health } \\
\text { behavior } \\
\text { research from } \\
\text { 2000 to 2005: } \\
\text { a systematic } \\
\text { review }\end{array}$ & $\begin{array}{l}\text { Type and extent of theory } \\
\text { use in behavioural } \\
\text { researches }\end{array}$ & $\begin{array}{l}\text { Use and } \\
\text { application of } \\
\text { behavioural } \\
\text { theories }\end{array}$ \\
\hline $\begin{array}{l}\text { ?eyrot and } \\
\text { Rubin (2007) } \\
\text { 22] }\end{array}$ & $\begin{array}{l}\text { Review } \\
\text { article }\end{array}$ & $\begin{array}{l}\text { Behavioral and } \\
\text { psychosocial } \\
\text { interventions in } \\
\text { Diabetes }\end{array}$ & $\begin{array}{l}\text { Key } \\
\text { behavioural/psychosocial } \\
\text { interventions for diabetes } \\
\text { patients }\end{array}$ & $\begin{array}{l}\text { Behavioural } \\
\text { theories, } \\
\text { behaviour change } \\
\text { techniques and } \\
\text { strategies, } \\
\text { providing effective } \\
\text { support, feasibility } \\
\text { issues }\end{array}$ \\
\hline ?restwich et & Original & Does theory & The extent and type of & The association \\
\hline
\end{tabular}




\begin{tabular}{|c|c|c|c|c|}
\hline $\begin{array}{l}\text { ㅊl. (2014) } \\
\text { 19] }\end{array}$ & research & $\begin{array}{l}\text { influence the } \\
\text { effectiveness of } \\
\text { health } \\
\text { behavior } \\
\text { interventions? } \\
\text { Meta-analysis }\end{array}$ & $\begin{array}{l}\text { theory use in physical } \\
\text { activity and dietary } \\
\text { interventions, and } \\
\text { association with } \\
\text { intervention effectiveness }\end{array}$ & $\begin{array}{l}\text { between theory } \\
\text { use and } \\
\text { intervention } \\
\text { effectiveness }\end{array}$ \\
\hline $\begin{array}{l}\text { Prochaska JJ } \\
\text { and } \\
\text { Prochaska } \\
\text { O (2011) } \\
47]\end{array}$ & $\begin{array}{l}\text { Review } \\
\text { article }\end{array}$ & $\begin{array}{l}\text { A review of } \\
\text { multiple health } \\
\text { behavior } \\
\text { change } \\
\text { interventions } \\
\text { for primary } \\
\text { prevention }\end{array}$ & $\begin{array}{l}\text { Reviewed randomized } \\
\text { clinical trials that have } \\
\text { evaluated multiple health } \\
\text { behaviour change } \\
\text { interventions }\end{array}$ & $\begin{array}{l}\text { Multiple behaviour } \\
\text { change } \\
\text { interventions }\end{array}$ \\
\hline $\begin{array}{l}\text { Prochaska et } \\
\text { al. (2008) } \\
\text {.48] }\end{array}$ & $\begin{array}{l}\text { Review } \\
\text { article }\end{array}$ & $\begin{array}{l}\text { Multiple health } \\
\text { behavior } \\
\text { change } \\
\text { research: An } \\
\text { introduction } \\
\text { and overview }\end{array}$ & $\begin{array}{l}\text { Conceptual and } \\
\text { methodological issues on } \\
\text { rationale and need for } \\
\text { multiple health behaviour } \\
\text { change research and } \\
\text { interventions }\end{array}$ & $\begin{array}{l}\text { Multiple lifestyle } \\
\text { behaviours } \\
\text { intervention }\end{array}$ \\
\hline $\begin{array}{l}\text { Rosland et } \\
\text { al. (2008) } \\
\text { 33] }\end{array}$ & $\begin{array}{l}\text { Original } \\
\text { research }\end{array}$ & $\begin{array}{l}\text { When is social } \\
\text { support } \\
\text { important? The } \\
\text { association of } \\
\text { family support } \\
\text { and } \\
\text { professional } \\
\text { support with } \\
\text { specific } \\
\text { diabetes self- } \\
\text { management } \\
\text { behaviors }\end{array}$ & $\begin{array}{l}\text { Tested whether } \\
\text { perceived family and } \\
\text { friend support } \\
\text { differentially affects } \\
\text { diabetes self- } \\
\text { management behaviour } \\
\text { compared to support } \\
\text { from health professionals }\end{array}$ & $\begin{array}{l}\text { Effect of family } \\
\text { and friend support } \\
\text { on diabetes self- } \\
\text { management } \\
\text { behaviours }\end{array}$ \\
\hline $\begin{array}{l}\text { Jan Dorsten } \\
\text { and Lindley } \\
\text { (2011) [26] }\end{array}$ & $\begin{array}{l}\text { Review } \\
\text { article }\end{array}$ & $\begin{array}{l}\text { Cognitive and } \\
\text { behavioral } \\
\text { approaches in } \\
\text { the treatment } \\
\text { of Obesity }\end{array}$ & $\begin{array}{l}\text { Cognitive and } \\
\text { behavioural components } \\
\text { of lifestyle interventions } \\
\text { for weight loss }\end{array}$ & $\begin{array}{l}\text { Cognitive- } \\
\text { behavioural } \\
\text { strategies for } \\
\text { weight loss, } \\
\text { behavioural } \\
\text { maintenance }\end{array}$ \\
\hline $\begin{array}{l}\text { Jenditti and } \\
\text { Kramer } \\
\text { (2012) [38] }\end{array}$ & $\begin{array}{l}\text { Review } \\
\text { article }\end{array}$ & $\begin{array}{l}\text { Necessary } \\
\text { components } \\
\text { for lifestyle } \\
\text { modification } \\
\text { interventions } \\
\text { to reduce } \\
\text { Diabetes risk }\end{array}$ & $\begin{array}{l}\text { Components and } \\
\text { translation of } \\
\text { behavioural lifestyle } \\
\text { interventions for } \\
\text { effective self- } \\
\text { management of diet, } \\
\text { activity, and weight }\end{array}$ & $\begin{array}{l}\text { Behaviour change } \\
\text { techniques and } \\
\text { strategies, modes } \\
\text { of delivering } \\
\text { lifestyle } \\
\text { interventions, } \\
\text { intervention } \\
\text { providers, } \\
\text { effective support } \\
\text { and follow-up }\end{array}$ \\
\hline $\begin{array}{l}\text { Jerheijden et } \\
\text { al. (2005) } \\
\text { 31] }\end{array}$ & $\begin{array}{l}\text { Review } \\
\text { article }\end{array}$ & $\begin{array}{l}\text { Role of social } \\
\text { support in } \\
\text { lifestyle- } \\
\text { focused weight } \\
\text { management } \\
\text { interventions }\end{array}$ & $\begin{array}{l}\text { Theoretical and practical } \\
\text { framework for social } \\
\text { support, the mechanisms } \\
\text { by which social support } \\
\text { affects weight loss and } \\
\text { weight loss maintenance }\end{array}$ & Social support \\
\hline
\end{tabular}


Eight key features/components and practical adaptation considerations of BLMls were emerged as themes (or important issues) from the included papers: understanding the target health behaviour, use of behavioural/psychological theories, applying behaviour change techniques and strategies, providing effective support and follow-up, intervention delivery formats and providers, cultural sensitivity, consideration of feasibility issues, and addressing multiple lifestyle behaviours. The synthesized results are presented below.

\section{Understanding the target health behaviour: multiple determinants and levels}

The development, change, and maintenance of health-related behaviours are influenced by a range of social, cultural, and economic factors [8]. There is no single factor or set of factors that adequately explain why people engage in unhealthy behaviours; rather, a broad understanding of the most important individual, social, economic, cultural, and policy factors can provide a basis for understanding health behaviours and inform the development of interventions [11]. Furthermore, lifestyle behaviours, like most health behaviours, are influenced by a complex interplay of factors at multiple levels (individual, social, environmental, and policy), and recognizing all types of influences can inform the development of multilevel interventions with the best chance of success [5].

Behavioural modification interventions should not only target individuals, but also interpersonal, organizational, and environmental factors; and this mindset is crucial in the design of BLMIs. As this process is complex and determined by factors at multiple levels, identifying the most influential factors for a particular person or population can help and enable intervention developers to focus on the most relevant issues, and strategies for influencing lifestyle behaviours will need to be informed by evidence on the most important behavioural determinants. In general, in order to increase the chance of developing successful BLMIs, program designers and researchers should be attentive to the various determinants and levels of influence that could affect individuals' and populations' behaviours in LMICs in a more pressing way, due to their prevalent and higher risk low-socioeconomic population group. To this end, behaviourand context-specific approaches are needed to comprehend these multiple determinants, which should consider not only the behaviour itself, but also the surrounding social, environmental, and policy influences on the target behaviour.

\section{Use of behavioural (psychological) health theories}

Theory is essential to intervention development because it provides a framework for researchers to design, implement, and evaluate the effects of health promotion programs $[11,18]$. Increasing evidence also suggests that public health and health promotion interventions developed with an explicit theoretical basis(s) are more effective than those developed without a theoretical basis. Additionally, some strategies that combine multiple theories and concepts have larger effects $[11,19]$. When BLMls are based on behavioural/psychological health theories, implemented effectively and skillfully using evidence-based principles, and measured accurately, they are more likely to improve lifestyle behaviours and health $[11,18$, 20]. Therefore, it is important to use relevant behaviour change theories to enhance the efficacy and adherence of BLMIs. 
Behaviour change interventions are usually designed using theory/model-based behaviour change strategies or by combining previously successful interventions. Self-determination theory, theory of planned behaviour, social cognitive theory, trans-theoretical model, and social-ecological model are among the most effective theories/models used in lifestyle behaviour change interventions [21]. Most behaviour change theories and models focus on four types of factors in BLMIs: motivators, inhibitors/facilitators, intentions, and triggers. Motivators are factors that predispose individuals to action, such as perceived need, perceived benefits of the intervention, outcome expectations, rewards/incentives, and cues to action. Inhibitors/facilitators are barriers to (i.e., resources, skills, or support) or enablers for action. Intentions are the proximal cause of behaviour change; and triggers are the events that shift a person from being predisposed to action into an action state [22]. It is important to understand how constructs of behaviour change theories are rigorously measured and analyzed in theory-based BLMls, including the measurement and analysis of potential behavioural mediators and moderators, as this is the building block of the evidence-base for change in health behaviour [23].

The selection of an appropriate theory should begin with identifying the problem, goal, and units of practice [11]. When deciding on which theories to use, it is crucial to consider how culture, context, and health problems can and should influence the selection and application of theories and interventions [18, 24]. In this regard, considerations on the practicability and generalizability of translating theory into realworld community settings or clinical practice, as well as empirically testing theories in the field, prior to their use in research, are beneficial $[8,11]$.

\section{Applying behaviour change techniques and strategies}

Behaviour change techniques (BCTs) and strategies that are more commonly applied in BLMls typically comprise a combination of information and skill rehearsal (educational interventions). The more common BCTs include goal setting, self-monitoring with feedback, motivational interviewing, problem-solving and coping skills training, environmental change (barrier reduction), behavioural contracting, use of incentives/rewards, relapse prevention, and social support [10,25]. These "packages" of BCTs can be linked to key behavioural targets and behaviour change, and they have shown positive results on BLMIs outcomes in several clinical trials [10]. Some important BCTs and strategies are outlined as follows.

Cognitive restructuring: Emotional factors can have a significant impact on a person's commitment to behaviour change; and participants are taught to recognize and modify their thoughts and beliefs concerning lifestyle behaviours through cognitive restructuring. Cognitive restructuring can be used to replace negative and punitive statements with statements that are encouraging, empowering, and affirming for participants who have a poor self-concept. Effective BCT packages frequently include cognitive approaches to identify and modify maladaptive thoughts or self-perceptions associated with unhealthy lifestyle behaviours. In this case, participants are taught to recognize and change maladaptive thoughts and emotions, such as dichotomous thinking and rationalizations [26].

Self-monitoring. It is often regarded as the most important component of BLMIs, and it has been found to be significantly associated with both short- and long-term health outcomes [9]. Participants are taught to 
write down or record everything (e.g., eating habits and frequency, minutes of exercise) and then use the diary to evaluate their current behaviour, identify problems, and select specific behaviours to target for change. Interventionists review participants' behavioural records and provide specific guidance and supportive feedback. In addition to providing feedback, self-recording can also help in establishing proper baseline values of behaviour, raising awareness of maladjusted behaviour patterns, and encouraging initial changes in the desired lifestyle behaviour.

However, frequent and thorough self-monitoring may cause behavioural fatigue among individuals, and considerations of the intensity of self-recording and its well-augmented use as a means of reinforcement may be warranted [26]. In addition, as adherence to self-monitoring tends to disappear over time, any potential access for the use of new technologies in research, such as smartphones or accelerometers, may be perceptively considered to make the task of self-monitoring easier [27].

Goal setting: It is a relatively simple technique and may be especially important for low socio-economic settings as it can be successfully taught to a wide range of people with varying educational and social backgrounds [10]. Self-help/self-care support is an important component of BLMls as it improves intervention compliance and motivates behaviour change. And typically, in BLMIs, participants are given goals and asked to monitor and modify these aspects of their behaviour. Although the overall behavioural goals are quite general (e.g., eat $1500 \mathrm{kcal} / \mathrm{d},<30 \%$ from fat, and exercise 150 minutes per week), more specific daily goals (e.g., take a daily 30 -minute walk) help break the behaviour change into small, achievable steps rather than a general goal. Goal setting can also be most effective when the goals are realistic, short-term, flexible, and set by the participant rather than imposed by interventionists [27].

Motivational Interviewing (MI): It is a person-centered approach that focuses on techniques that help participants/patients address their self-motivation to change behaviour. The role of interventionists in MI is not to provide advice or information, as these actions may be perceived as insensitive to the person's personal needs, leading to a breakdown in communication. Rather, the main focus is to have most of the conversation that guides the process in order to encourage the research participant to internalize the change process and make the decision to change. It is considered as a collaborative conversation between the interventionist/practitioner and the participant/patient, with the goal of bringing about change and overcoming barriers to change. Every MI intervention should include at least these three $\mathrm{MI}$ skills that reflect the engaging, focusing, and evoking processes of Ml: mastery of a person-centered counseling style, clear identification of one or more change goals toward which the intervention is directed, and differential evocation of participants' own motivational statements (change talk) to increase the participants'/patients' readiness to change [28].

Stimulus control: As environmental factors play a role in influencing lifestyle behaviours, most lifestyle interventions teach stimulus control techniques to reduce cues for unhealthy behaviours and strengthen cues for healthy behaviour. The aim of stimulus control techniques is to reorganize the environment to support desired behaviours. Participants are instructed to reduce or eliminate cues that encourage unhealthy behaviours (for example, remove chips, desserts, or other tempting foods from the house) and to make good choices as simple as possible (for example, having low-fat snacks readily available) [26]. 
This kind of behavioural strategy is more common in meal-replacement and partial-meal-replacement programs, which usually replace one or two meals per day with a portion-controlled, vitamin and mineral fortified low-energy meal. In addition to the benefit of balanced nutrient content, these meal replacement techniques provide opportunities to educate participants about proper portion sizes, and they reduce the probability of poor food choices by restricting meal options [29].

Relapse prevention: While long-term adoption of lifestyle behaviours is imperative for lowering chronic disease risk, many people find it challenging to maintain health habits over time. Participants need taught to identify specific situations that might pose problems for their behavioural adherence, how to use behavioural and cognitive coping strategies, and how to apply problem-solving techniques to overcome barriers and prevent behavioural relapse. As most individuals are faced with competing priorities and other demands in life (including work, family, and community obligations) that make it difficult to adhere to a healthy lifestyle, initiating and maintaining a healthy lifestyle requires a good deal of time, planning, and organization, and intervention providers can play a meaningful role in helping participants to prioritize behavioural changes that will be beneficial to supporting long-term adherence [30]. This will likely require supporting individuals to reprioritize their current investment of time and resources to support behavioural adherence to meaningful changes.

Social support: Support from a spouse, family, or significant other is an important factor in influencing participation in lifestyle behaviour change interventions. It is also a powerful tool to help people succeed in making and sustaining behavioural changes, and it could be used to improve motivation for individuals at the greatest risk of failing in their attempts at lifestyle change [31, 32]. Involving family members has been found to be central for lifestyle behaviour change [33-35], and efforts to engage family members in BLMls must be well coordinated to achieve good intervention success. Family involvement and support are important because an individual's lifestyle behaviours are likely to mirror those of the people with whom they live and have close relationships.

\section{Providing effective support and follow-up}

When dealing with chronic rather than acute health conditions, long-term support is expected, and an integrated set of interventions as a behaviour change support process consists of a step-by-step approach in which interventions occur in a specific sequence while taking individual contexts into account (i.e. tailoring or personalizing of the intervention). It is preferable to begin the behaviour change support process with issues that trouble the participant from implementing the intervention actions (participantcentered approach). This approach increases participants' confidence in their own abilities to change their behaviour and achieve the intervention goal/s [22].

Behavioural gains are best maintained when the intervention includes routine ongoing follow-up support. This is not usually straightforward, and it is important to be aware of common challenges from participants during the implementation stage [30]. Establishing an ongoing participant-provider strong partnership and tracking system have also revealed good intervention success in terms of enhancing intervention sustainability [36]. 


\section{Intervention delivery formats and providers}

\section{Intervention delivery formats}

Lifestyle behaviour change interventions can be delivered in diverse settings, including clinics, workplaces, community settings, and homes. It also appears that BLMls can be delivered through a variety of different intervention delivery formats, such as face-to-face (in-person), media outlets (print media, television, and radio), digital/mHealth/telehealth technologies, the Internet, potential new ways of communication (i.e. messaging via social medias), or combinations of these options (multicomponent-based) [37]. Recent advances in technology have also created new ways for individuals to track their diet, physical activity, and weight. In the planning of BLMls for specific target groups (youths, adults, etc.), there should be an emphasis on efforts to identify effective delivery alternatives, with ongoing potential opportunities for personal interaction with clinicians, health educators, and counselors. Although conducting the intervention in-person is likely to maximize adherence, providing effective BLMIs with minimal human interaction may be possible with the use of other modes to significantly reduce costs and greatly improve the scalability of interventions. Indeed, the transition to a reduced session frequency and other contact options besides face-to-face is motivated not only by the provider's cost concerns (e.g., time, space, labor, materials, and access) and the advantage of improved scalability, but also by competing demands, motivational plateaus, and intervention/treatment fatigue on the part of the participant.

Technology-based remotely delivered interventions (telephone interventions, internet interventions) have high reachability to a large number of people. These interventions represent less-intensive formats allowing for greater flexibility, long-term delivery of the intervention, and substantially less time and resources for administration [37]. However, concerns about access, literacy status of participants, and weak ICT infrastructure may hamper their widespread application in LMICs. Thus, a critical exploitation of the potential effective usage of these technology-based intervention delivery formats in LMICs is desired in the design of BLMIs. For example, the support of digital technologies (telehealth, mHealth) can enable the routine gathering and exchange of meaningful information, facilitating home monitoring of BLMIs. Furthermore, advances in social media can offer a novel approach to lifestyle and behavioural interventions for sharing of intervention experiences and effective exchange of testimonials between individuals to improve social support and adherence to BLMIs.

\section{Intervention providers}

The selection and cost of interventionists raises another important question: who can be trained to deliver effective interventions, what type of training and ongoing supervision is required, and who is available to provide the necessary "master training" to sustain scalable models of behavioural intervention in the population at large [38]. BLMls are delivered by trained interventionists including health professionals (such as health counselors, registered dietitians, exercise specialists, or psychologists) or, less often, by trained laypersons. Community health workers and lay health educators/health coaches, who are members of the community and role models due to their personal history of healthy lifestyles, have been trained to administer behavioural interventions in an effort to widen the reach of BLMIs into more 
community settings [38]. The sustainability of lay interventionist workforce models and how they can be best integrated into community-based health care delivery systems need further exploration in LMICs. In this regard, monitoring the level of training adequacy and quality for providers, as well as field observation for intervention fidelity and dosage, should be briefly described in intervention protocols and result reporting.

\section{Cultural sensitivity/adaptability}

Culture influences health behaviours, and the cultural sensitivity of a behavioural intervention should incorporate observable aspects of a local culture in the intervention content. When designing BLMIs, the "one-size-fits-all" approach does not work; interventions must address the cultural practices and value systems of the cultural (or subcultural) group; and tailoring the intervention to specific cultural norms and preferences of the target population is considered beneficial. People are more interested in health messages when they are approached in a culturally sensitive manner. In addition, culturally appropriate advice can be easier to implement straightaway because participants do not have to modify the advice on their own to account for common lifestyle choices in their community [39-41].

Cultural adaptability/sensitivity is the middle ground between two extreme positions: a universal approach (a "top-down" approach) vs a culture-specific approach (a "bottom-up" approach). A culture-specific approach (a "bottom-up" approach) emphasizes culturally grounded content consisting of the unique values, beliefs, and customs of a particular culture, while a universal approach (a "top-down" approach) views the original intervention's content as applicable to all cultural groups and does not require any modification. Therefore, cultural sensitivity is not essentially a "top-down" intervention modification, but rather a set of procedures that integrate both "top-down" and "bottom-up" approaches through a series of adaptation stages that include meaningful input from the cultural group members themselves. The fundamental theories and procedures from the initial efficacy trials are used as a basis ("top-down" elements), and the original intervention protocol is modified with input from cultural group members at various stages ("bottom-up" elements) to improve the adapted-version intervention. In this regard, informed judgments from a community advisory panel, which may include members of cultural groups, are required; and quantitative and qualitative methods, such as focus groups, literature searches, or surveys, can be combined to inform modifications and guide culturally sensitive intervention design [39, 42].

\section{Feasibility issues}

Feasibility or practicability is an important aspect in designing BLMIs or health promotion interventions in general. This includes considerations that how much the designed intervention and the implementation of its components are applicable in "real-world" settings and can be widely scaled up to the target population [43].

Lifestyle behaviour change interventions should not go unused or underutilized by their intended audience; therefore, it may be useful to gain a better understanding of the intervention users/target group, potential 
practitioners, and the health system at large. To this end, conducting implementation feasibility or pilot studies prior to the full intervention trial $[43,44]$ and reaching out and consulting potential relevant stakeholders (local health care providers, community agents, local administrate, community organizations, etc.) during the development process [45] can benefit in identifying potential refinements and make the intervention pragmatic - rather than theoretical. Moreover, improving the external validity of the research enables for greater generalizability of the proposed intervention to "real-world" settings [46].

\section{Addressing multiple lifestyle behaviours}

Multiple unhealthy behaviours often co-occur together, and the multiple health behaviour change approach is based on the presumption that success in changing one or more lifestyle behaviours may increase one's confidence or self-efficacy to improve risk behaviours for which individuals have low motivation to change. As such, health behaviour change may serve as a gateway to a more healthful way of life. Targeting change in multiple risk behaviours has the potential to capitalize on beneficial synergies to increase health impact, maximize health promotion, and increase cost-effectiveness $[47,48]$. However, there is little understanding of the relative advantages of simultaneous versus sequential delivery of multiple behaviour change interventions [49].

\section{Discussion}

This review intended to provide knowledge as a call to action for researchers in LMICs to address the need for behavioural interventions that target lifestyle behaviours relevant for NCDs prevention and control by outlining the key features/components of BLMIs and some practical considerations. The design of BLMIs needs an understanding and consideration of different aspects, and these are highlighted as the most important issues that researchers and planners should be aware of when developing behaviour change programs and interventions.

Addressing the increasing burden of NCDs in LMICs has become a global priority, and more focus is needed on identifying successful and cost-effective preventive interventions that can be contextually adapted to the conditions of these countries $[6,50]$. The World Health Organization (WHO) recommended "best buy" options which target the four key modifiable behavioural risk factors for NCDs [51]. However, there are major challenges in delivering of these "best buys" in local LMIC contexts with fidelity [52], which could suggest that interventions need, of course, be tailored to LMIC settings and should be sensible to the social, economic, and cultural aspects of target communities if the approaches are to be effective [53]. In this respect, beyond individual-focused interventions, approaches that address larger social, environmental, and policy issues through multisectoral and multistakeholder actions are more important in bringing about behavioural changes in lifestyles that could essentially promote healthy living and impact the reduction of NCDs [54]. Consequently, having an understanding of comprehensive socioecological approaches is vital in efforts to address target lifestyle behaviours in LMICs [11].

In most LMICs, the number of public health intervention studies focusing on behavioral risk factors for NCD prevention and control remains limited $[55,56]$. There is a scarcity of locally appropriate evidence on 
how to apply health promotion interventions that could potentially be impactful in reducing the current rising burden of NCDs in LMIC contexts, and as a result, many LMICs struggle with NCD policy implementation gaps [57-61]. Likewise, sound research evidences are required on each specific issue pinpointed in this review to determine the most effective ways of specific approaches that should be followed to achieve great success in changing lifestyle behaviours in LMIC contexts. Accordingly, novel original researches and systematic reviews that favor the identification of more specific, culturallyoriented, and feasible BLMls are urged.

Furthermore, while BLMIs are opted as they are more cost-effective and viable options for controlling chronic NCDs, LMIC health systems are markedly less well-versed in integrating them into other public health priority services $[7,62,63]$. This can be reflected in the focus of most LMICs' primary health care (PHC) systems, which were designed and continue to deliver preventive and curative services primarily for communicable diseases, rather than becoming integrative for the rising burden of NCDs $[62,64]$. To tackle the NCD epidemic and respond to the greatest public and global health needs, LMIC health systems should now take action and leverage BLMIs in preventive and curative health service delivery through recognizing existing PHC and continuum-of-care approaches [65-69].

This review should be examined in light of some limitations. Primarily, this review is not exhaustive but is intended to provide a overview of relevant literature; and this approach may have resulted in the loss of information in some topics. A second limitation is that some detailed methodological aspects (e.g., ways to improve recruitment and retention of study participants, procedures, or methods to ensure intervention fidelity), which are noticeably important when designing behavioural interventions, were not discussed. Despite these limitations, this review provides a resource on the current understanding about BLMIs, and how and with what perspectives this knowledge can be applied to design BLMIs in LMIC settings and beyond.

\section{Conclusion}

The alarming rise in incidence and prevalence rates of NCDs in LMICs in recent years demands attention for the need to embark on effective and viable interventions. Thus, targeting BLMIs should be a national health priority for LMICs, which in turn, needs a proper understanding of their essential design components, as well as practical contextual considerations, as an important first step. In this regard, our review identified eight key features and practical considerations of BLMIs: understanding the target behaviour, using behavioural theories, applying behaviour change techniques and strategies, providing effective support and follow-up, intervention delivery formats and providers, cultural sensitivity, feasibility consideration, and addressing multiple lifestyle behaviours.

It is noticeable that the health systems of LMICs should be accommodative for such potentially impactful interventions and initiatives through applying innovative and comprehensive approaches in current NCDs prevention and treatment practices. Furthermore, the development of BLMIs requires an interdisciplinary approach and integrating experts from different mix of health and social science (e.g. psychology) disciplines in this field is worthwhile. The limitations of this review also justify the need for original 
researches and systematic reviews on each specific feature or theme of BLMIs to identify successful and feasible interventions which could work best in LMIC contexts.

\section{Abbreviations}

BLMIs: Behavioural and lifestyle modification interventions

BCTs: Behaviour change techniques

LMICs: Low- and middle-income countries

NCDs: Non-communicable diseases

\section{Declarations}

Ethical approval and consent to participate

Not applicable

Consent for publication

Not applicable

\section{Availability of data and materials}

This is a literature review; data is contained within the article.

\section{Conflict of Interests}

The authors declare no conflict of interest.

\section{Acknowledgements}

The authors would like to thank for the financial support from the Addis Ababa University Themaic Research Fund.

\section{Contribution of authors}

Conceptualization: AN, AW and EG; Planned search strategy and data extraction: AN; Data synthesis, analysis and interpretation: AN, AA, AW and EG; Writing - original draft preparation: AN; Writing - review, editing, and provided critical insights: AA, AW and EG. All authors have read and agreed to the published version of the manuscript.

\section{References}


References marked with an asterisk indicate the most relevant literature.

1. World Health Organization. Why is 2018 a strategically important year for NCDs; 2018. https://www.who.int/ncds/governance/high-level-commission/why-2018-importantyear-for-NCDs.pdf

2. GBD 2016 Causes of Death Collaborators. Global, regional, and national age-sex specific mortality for 264 causes of death, 1980-2016: a systematic analysis for the Global Burden of Disease Study 2016. Lancet. 2017;390(10100):1151-1210. doi: 10.1016/S0140-6736(17)32152-9.

3. GBD 2015 DALYs and HALE Collaborators. Global, regional, and national disability-adjusted life-years (DALYs) for 315 diseases and injuries and healthy life expectancy (HALE), 1990-2015: a systematic analysis for the Global Burden of Disease Study 2015. Lancet. 2016;388(10053):1603-1658. doi: 10.1016/S0140-6736(16)31460-X.

4. World Health Organization. Overview-Preventing chronic diseases: a vital investment. https://www.who.int/chp/chronic_disease_report/en/

5. Arena R, Guazzi M, Lianov L, Whitsel L, Berra K, Lavie CJ, et al. Healthy lifestyle interventions to combat non-communicable disease-a novel nonhierarchical connectivity model for key stakeholders: a policy statement from the American Heart Association, European Society of Cardiology, European Association for Cardiovascular Prevention and Rehabilitation, and American College of Preventive Medicine. Eur Heart J. 2015;36(31):2097-109. doi: 10.1093/eurheartj/ehv207.

6. World Health Organization. Global action plan for the prevention and control of non-communicable diseases: 2013-2020. Geneva, Switzerland; 2013.

7. Atun R, Jaffar S, Nishtar S, Knaul FM, Barreto ML, Nyirenda M, et al. Improving responsiveness of health systems to non-communicable diseases. Lancet. 2013;381(9867):690-7. doi: 10.1016/S01406736(13)60063-X.

8. *Glanz K, Rimer BK, Viswanath K. Health behavior and health education: Theory, research, and practice. 4th ed. San Francisco, CA: Jossey-Bass; 2008.

9. Michie S, Abraham C, Whittington C, McAteer J, Gupta S. Effective techniques in healthy eating and physical activity interventions: a meta-regression. Health Psychol. 2009;28(6):690-701. doi: $10.1037 / \mathrm{a} 0016136$.

10. *Michie S, Jochelson K, Markham WA, Bridle C. Low-income groups and behaviour change interventions: a review of intervention content, effectiveness and theoretical frameworks. J Epidemiol Community Health. 2009;63(8):610-22. doi: 10.1136/jech.2008.078725.

11. *Glanz K, Bishop DB. The role of behavioral science theory in development and implementation of public health interventions. Annu Rev Public Health. 2010; 31:399-418. doi:

10.1146/annurev.publhealth.012809.103604. 
12. World Health Organization. Global health estimates 2016: deaths by cause, age, sex, by country and by region, 2000-2016. Geneva; 2018.

13. World Health Organization. Noncommunicable diseases country profiles 2018. Geneva; 2018.

14. Fan H, Song F. An assessment of randomized controlled trials (RCTs) for non-communicable diseases (NCDs): more and higher quality research is required in less developed countries. Sci Rep. 2015;5:13221. doi: $10.1038 /$ srep13221.

15. Heneghan C, Blacklock C, Perera R, Davis R, Banerjee A, Gill P, et al. Evidence for non-communicable diseases: analysis of Cochrane reviews and randomised trials by World Bank classification. BMJ Open. 2013;3(7):e003298. doi: 10.1136/bmjopen-2013-003298.

16. Jones AC, Geneau R. Assessing research activity on priority interventions for non-communicable disease prevention in low- and middle-income countries: a bibliometric analysis. Glob Health Action. 2012;5:1-13. doi: 10.3402/gha.v5i0.18847.

17. Green BN, Johnson CD, Adams A. Writing narrative literature reviews for peer-reviewed journals: secrets of the trade. J Chiropratic Medicine 2006; 5:101-117

18. * Green LW, Kreuter MW. Health promotion planning: An educational and ecological approach. 4 th ed. New York McGraw-Hill; 2005.

19. Prestwich A, Sniehotta FF, Whittington C, Dombrowski SU, Rogers L, Michie S. Does theory influence the effectiveness of health behavior interventions? Meta-analysis. Health Psychol. 2014;33(5):465-74. doi: $10.1037 / \mathrm{a} 0032853$.

20. *Bartholomew Eldregde LK, Markham CM, Ruiter RAC, Fernàndez ME, Kok G, Parcel GS. Planning health promotion programs: An intervention mapping approach. 4th ed. Hoboken NJ: Wiley; 2016.

21. Linke SE, Robinson CJ, Pekmezi D. Applying psychological theories to promote healthy lifestyles. Am J Lifestyle Med. 2014;8(10).

22. Peyrot M, Rubin RR. Behavioral and psychosocial interventions in diabetes: a conceptual review. Diabetes Care. 2007;30(10):2433-40. doi: 10.2337/dc07-1222.

23. Painter JE, Borba CP, Hynes M, Mays D, Glanz K. The use of theory in health behavior research from 2000 to 2005: a systematic review. Ann Behav Med. 2008;35(3):358-62. doi: 10.1007/s12160-008-9042-y.

24. Noar SM, Chabot M, Zimmerman RS. Applying health behavior theory to multiple behavior change: considerations and approaches. Prev Med. 2008;46(3):275-80.

25. *Michie S, Richardson M, Johnston M, Abraham C, Francis J, Hardeman W, et al. The behavior change technique taxonomy ( $\mathrm{v} 1)$ of 93 hierarchically clustered techniques: building an international consensus for 
the reporting of behavior change interventions. Ann Behav Med. 2013;46(1):81-95. doi: 10.1007/s12160013-9486-6.

26. Van Dorsten B, Lindley EM. Cognitive and behavioral approaches in the treatment of obesity. Med Clin North Am. 2011;95(5):971-88. doi: 10.1016/j.mcna.2011.06.008.

27. Burke LE, Styn MA, Sereika SM, Conroy MB, Ye L, Glanz K, et al. Using mHealth technology to enhance self-monitoring for weight loss: a randomized trial. Am J Prev Med. 2012;43(1):20-6. doi:

10.1016/j.amepre.2012.03.016.

28. *Miller WR, Rollnick S. Motivational interviewing: helping people change. 3rd ed. New York: Guilford Press; 2013.

29. Hagobian TA, Phelan S. Lifestyle interventions to reduce Obesity and Diabetes. Am J Lifestyle Med. 2013; 7(84).

30. Johnston CA, Moreno JP. Promotion of long-term adherence to a healthy lifestyle. Am J Lifestyle Med. 2014; 8(239).

31. Verheijden MW, Bakx JC, van Weel C, Koelen MA, van Staveren WA. Role of social support in lifestylefocused weight management interventions. Eur J Clin Nutr. 2005;59 Suppl 1:S179-86. doi:

10.1038/sj.ejcn.1602194.

32. Miller TA, Dimatteo MR. Importance of family/social support and impact on adherence to diabetic therapy. Diabetes Metab Syndr Obes. 2013;6:421-6. doi: 10.2147/DMSO.S36368.

33. Rosland AM, Kieffer E, Israel B, Cofield M, Palmisano G, Sinco B, et al. When is social support important? The association of family support and professional support with specific diabetes selfmanagement behaviors. J Gen Intern Med. 2008;23(12):1992-9.

34. *Kang CM, Chang SC, Chen PL, Liu PF, Liu WC, Chang CC, et al. Comparison of family partnership intervention care vs. conventional care in adult patients with poorly controlled type 2 diabetes in a community hospital: a randomized controlled trial. Int J Nurs Stud. 2010;47(11):1363-73. doi: 10.1016/j.jpurstu.2010.03.009.

35. *Mayberry LS, Osborn CY. Family support, medication adherence, and glycemic control among adults with type 2 diabetes. Diabetes Care. 2012;35(6):1239-45. doi: 10.2337/dc11-2103.

36. Besculides M, Zaveri H, Hanson C, Farris R, Gregory-Mercado K, Will J. Best practices in implementing lifestyle interventions in the WISEWOMAN program: adaptable strategies for public health programs. Am J Health Promot. 2008;22(5):322-8. doi: 10.4278/ajhp.22.5.322.

37. Artinian NT, Fletcher GF, Mozaffarian D, Kris-Etherton P, Van Horn L, Lichtenstein AH, et al. Interventions to promote physical activity and dietary lifestyle changes for cardiovascular risk factor reduction in adults: 
a scientific statement from the American Heart Association. Circulation. 2010;122(4):406-41. doi: 10.1161/CIR.0b013e3181e8edf1.

38. *Venditti EM, Kramer MK. Necessary components for lifestyle modification interventions to reduce diabetes risk. Curr Diab Rep. 2012;12(2):138-46. doi: 10.1007/s11892-012-0256-9.

39. *Barrera M Jr, Castro FG, Strycker LA, Toobert DJ. Cultural adaptations of behavioral health interventions: a progress report. J Consult Clin Psychol. 2013;81(2):196-205. doi: 10.1037/a0027085.

40. Castro FG, Barrera M Jr, Holleran Steiker LK. Issues and challenges in the design of culturally adapted evidence-based interventions. Annu Rev Clin Psychol. 2010;6:213-39. doi: 10.1146/annurev-clinpsy033109-132032.

41. *Noar SM, Benac CN, Harris MS. Does tailoring matter? Meta-analytic review of tailored print health behavior change interventions. Psychol Bull. 2007;133(4):673-93. doi: 10.1037/0033-2909.133.4.673.

42. Coupe N, Cotterill S, Peters S. Tailoring lifestyle interventions to low socio-economic populations: a qualitative study. BMC Public Health. 2018;18(1):967. doi: 10.1186/s12889-018-5877-8.

43. Pearson N, Naylor PJ, Ashe MC, Fernandez M, Yoong SL, Wolfenden L. Guidance for conducting feasibility and pilot studies for implementation trials. Pilot Feasibility Stud. 2020; 6(167).

44. Eldridge SM, Lancaster GA, Campbell MJ, Thabane L, Hopewell S, Coleman CL, et al. Defining feasibility and pilot studies in preparation for randomised controlled trials: development of a conceptual framework. PLoS One. 2016;11(3):e0150205. doi: 10.1371/journal.pone.0150205.

45. Hawkins J, Madden K, Fletcher A, Midgley L, Grant A, Cox G, et al. Development of a framework for the co-production and prototyping of public health interventions. BMC Public Health. 2017;17(1):689. doi: 10.1186/s12889-017-4695-8.

46. *Glasgow RE. What types of evidence are most needed to advance behavioral medicine? Ann Behav Med. 2008;35(1):19-25. doi: 10.1007/s12160-007-9008-5.

47. Prochaska JJ, Prochaska JO. A review of multiple health behavior change interventions for primary prevention. Am J Lifestyle Med. 2011;5(3):10.1177/1559827610391883. doi:

$10.1177 / 1559827610391883$.

48. Prochaska JJ, Spring B, Nigg CR. Multiple health behavior change research: an introduction and overview. Prev Med. 2008;46(3):181-8. doi: 10.1016/j.ypmed.2008.02.001.

49. *Geller K, Lippke S, Nigg CR. Future directions of multiple behavior change research. J Behav Med. 2017;40(1):194-202. doi: 10.1007/s10865-016-9809-8.

50. WHO. Noncommunicable Disease. Fact Sheet. April 13, 2021. Available at: http://who.int/mediacentre/factsheets/fs355/en/ 
51. WHO. Tackling NCDs: "Best Buys" and other recommended interventions for the prevention and control of non-communicable diseases; 2017 Available at: http://apps.who.int/iris/bitstream/10665/259232/1/WHO-NMH-NVI-17.9-eng.pdf?ua1/141

52. Allen LN, Pullar J, Wickramasinghe K, Williams J, Foster C, Roberts N, et al. Are WHO "best buys" for non-communicable diseases effective in low-income and lower middle-income countries? A systematic review. Lancet Glob Health. 2017;(5 Suppl 1):S17.

53. Breda J, Wickramasinghe K, Peters DH, Rakovac I, Oldenburg B, Mikkelsen B et al. One size does not fit all: implementation of interventions for non-communicable diseases. BMJ. 2019; 367:16434 doi:10.1136/bmj.16434.

54. Marmot M, Bell R. Social determinants and non-communicable diseases: time for integrated action. BMJ. 2019;364:I251 doi:10.1136/bmj.I251.

55. Allen LN, Fox N, Ambrose A. Quantifying research output on poverty and non-communicable disease behavioural risk factors in low income and lower middle-income countries: a bibliometric analysis. BMJ Open. 2017;7:e014715. doi: 10.1136/bmjopen-2016-014715.

56. Ebrahim S, Pearce N, Smeeth L, Casas JP, Jaffar S, Piot P. Tackling non-communicable diseases in low- and middle-income countries: is the evidence from high-income countries all we need? PLoS Med. 2013;10(1):e1001377. doi: 10.1371/journal.pmed.1001377.

57. Allen LN, Nicholson BD, Yeung BYT, Goiana-da-Silva F. Implementation of non-communicable disease policies: a geopolitical analysis of 151 countries. Lancet Glob Health. 2020;8(1):e50-e58. doi: 10.1016/S2214-109X(19)30446-2.

58. Allen LN, Pullar J, Wickramasinghe KK, Williams J, Roberts N, Mikkelsen B, et al. Evaluation of research on interventions aligned to WHO 'Best Buys' for NCDs in low-income and lower-middle-income countries: a systematic review from 1990 to 2015. BMJ Glob Health. 2018;3(1):e000535. doi: 10.1136/bmjgh-2017000535 .

59. Shanthi Mendis, The policy agenda for prevention and control of non-communicable diseases. British Medical Bulletin. 2010; 96 (1): 23-43 https://doi.org/10.1093/bmb/ldq037

60. Shiroya V, Neuhann F, Müller O, Deckert A. Challenges in policy reforms for non-communicable diseases: the case of diabetes in Kenya. Glob Health Action. 2019;12(1):1611243. doi:

10.1080/16549716.2019.1611243.

61. Mukanu MM, Zulu JM, Mweemba C, Mutale W. Responding to non-communicable diseases in Zambia: a policy analysis. Health Res Policy Syst. 2017 Apr 24;15(1):34. doi: 10.1186/s12961-017-0195-7.

62. Allotey P, Reidpath DD, Yasin S, Chan CK, de-Graft Aikins A. Rethinking health-care systems: a focus on chronicity. Lancet. 2011 Feb;377(9764):450-1. doi: 10.1016/S0140-6736(10)61856-9. 
63. Atun R, Jaffar S, Nishtar S, Knaul FM, Barreto ML, Nyirenda M, et al. Improving responsiveness of health systems to non-communicable diseases. Lancet. 2013; 23;381(9867):690-7. doi: 10.1016/S01406736(13)60063-X.

64. Allotey P, Davey T, Reidpath DD. NCDs in low and middle-income countries - assessing the capacity of health systems to respond to population needs. BMC Public Health. 2014;14 Suppl 2(Suppl 2):S1. doi: 10.1186/1471-2458-14-S2-S1.

65. Alwan A, Maclean DR. A review of non-communicable disease in low- and middle-income countries. Int Health. 2009;1(1):3-9. doi: 10.1016/j.inhe.2009.02.003.

66. Varghese C, Nongkynrih B, Onakpoya I, McCall M, Barkley S, Collins TE. Better health and wellbeing for billion more people: integrating non-communicable diseases in primary care. BMJ. 2019;364:I327. doi: 10.1136/bmj.I327.

67. Demaio AR, Kragelund Nielsen K, Pinkowski Tersbøl B, Kallestrup P, Meyrowitsch DW. Primary Health Care: a strategic framework for the prevention and control of chronic non-communicable disease. Glob Health Action. 2014;7:24504. doi: 10.3402/gha.v7.24504.

68. Checkley W, Ghannem H, Irazola V, Kimaiyo S, Levitt NS, Miranda JJ, Niessen L, Prabhakaran D, Rabadán-Diehl C, Ramirez-Zea M, Rubinstein A, Sigamani A, Smith R, Tandon N, Wu Y, Xavier D, Yan LL; GRAND South Network, UnitedHealth Group/National Heart, Lung, and Blood Institute Centers of Excellence. Management of NCD in low- and middle-income countries. Glob Heart. 2014;9(4):431-43. doi: 10.1016/j.gheart.2014.11.003.

69. Thapa R, Zengin A, Thrift AG. Continuum of care approach for managing non-communicable diseases in low- and middle-income countries. J Glob Health. 2020;10(1):010337. doi: 10.7189/jogh.10.010337. 